\title{
THE TOXICANT-WILDLIFE COMPLEX
}

\author{
Donald G. CRosBy \\ Department of Environmental Toxicology, University of California, \\ Davis, California, USA
}

\begin{abstract}
Familiar vertebrate wildlife comprise less than five per cent of the animal kingdom. A major proportion of the other thousands of non-insect species are aquatic and will be increasingly exposed to a wide variety of manmade and natural chemicals. Effective management of this toxicant-wildlife complex demands general and simple means for the prediction and estimation of effects and hazards.

Direct, non-food exposure to toxicants is much more extensive than was expected and the bioconcentration of persistent compounds may be approximated by their lipid-water partition coefficients. Simple measures of distribution into soil organic matter and biota, environmental degradation, and toxicity then provide an estimate of relative hazard, extended and verified by both direct measurement and comparison of metabolites excreted by aquatic species and by predictive in vitro simulation of primary metabolism.

These generalizations suggest that bioconcentration of stable substances usually will depend upon the fat content of individuals, may not be strongly affected by metabolism, will not inevitably lead to 'biomagnification', and will become increasingly predictive.
\end{abstract}

\section{INTRODUCTION}

One of the major reasons behind the present interest in the dispersion dynamics of pollutants in the environment is concern over the possibility of unintentional but adverse effects on the world's biota. Indeed, this concern seems to have emerged with the advent of synthetic organic pesticides, and the harmful potential of these chemicals against wildlife-long prewarned by Rudd $^{1}$ and others-received its most dramatic description in Rachel Carson's controversial book Silent Spring ${ }^{2}$.

To most of us, the word 'wildlife' brings visions of vast herds on the African plains, magestic deer and elk of the American forest, or-as in Carson's book - the songbirds of May. By far the major part of previous scientific research on the effects of pesticides on wild animals has concentrated on fish and game of economic or sporting value, or on bird life. Their size, vocal ability, terrestrial habit, or familiar shape often thrust them upon our attention, although all of the world's birds, mammals, fish, amphibians and reptiles-the vertebrates-comprise only about five per cent of the described animal species (Table 1). Most of the others escape 
our notice; small, shy and silent, we perceive them only through their shadows in a sunlit pool or a furtive movement in the grass. Of the millionodd animal species accounted on earth today, at least 700000 are insects. Other invertebrates add a quarter-million species, while the higher animals so familiar to us account for well under 50000. Fewer than one hundred species really have been domesticated; the others should have equal claim to the name 'wildlife'.

Table 1. Some representatives of the animal kingdom

\begin{tabular}{lrl}
\hline \multicolumn{1}{c}{ Phylum } & $\begin{array}{c}\text { Number of } \\
\text { species }\end{array}$ & Example \\
\hline Coelenterata (coelentrates) & 9000 & Coral \\
Platyhelminthes (flatworms) & 9000 & Tapeworm \\
Nematoda (nematodes) & 10500 & Hookworm \\
Bryozoa (moss animals) & 6000 & 'Seaweed' \\
Mollusca (molluscs) & 40000 & Snail \\
Annelida (segmented worms) & 6000 & Earthworm \\
Arthropoda & 27000 & Crab \\
$\quad$ Crustacea (crustaceans) & 700000 & Ant \\
Insecta (insects) & 5000 & Sea star \\
Echinodermata (echinoderms) & & \\
Vertebrata (vertebrates) & 20000 & Salmon \\
$\quad$ Pisces (fish) & 8500 & Hawk \\
Aves (birds) & 6000 & Rattlesnake \\
Reptilia (reptiles) & 1500 & Frog \\
Amphibia (amphibians) & 5000 & Cat \\
Mammalia (mammals) & & \\
\hline
\end{tabular}

Of all the lower animals, we undoubtedly know most about insects. Some, such as the butterflies and lady beetles (Epilackna borealis), are coloured; others, such as the cicada (Magicicada septemdecim), are noisy; still others, including the mosquito and codling moth (Carpocapsa pomonella) cause irritation, disease or destruction. Obviously, there exists a very large body of data on the effects of chemicals on prominent members of the Insecta (and to a lesser extent their arthropod relatives, the Acarina or mites). Nematodes responsible for animal and plant diseases also have received some chemical attention, as have a few worms and economically-important molluscs. The reef-building corals, tasty crabs and lobsters, zooplankton which form the animal base of the world's aquatic food chains, and the host of animals whose shells one collects at the seashore are largely chemical and biochemical mysteries.

A large proportion of the non-insect invertebrates live in water, and they provide good examples of the toxicant-wildlife complex. Aside from their economic and ecological importance, anyone who has peered under the surface of a tropical lagoon or examined a drop of pond water under the microscope must attest to their astounding beauty and diversity of form. This diversity is compounded because many aquatic animals go through anatomically-distinct stages of development; the well-known 'jelly-fish', for 
example, have tiny plantlike colonial hydroids for 'parents', and the crabs scuttling along the beach are the adult product of fantastic zoea and megalops forms which long were considered to be separate species.

This invertebrate world is one of contrasts and excesses. The shell length of an oyster larva is about $70 \mu \mathrm{m}$, while that of the giant clam, Tridacna, often exceeds $1 \mathrm{~m}$; a free-swimming zoea $0.1 \mathrm{~mm}$ long becomes a crab which weighs a kilogram and climbs trees; a sedentary green sea anemone $0.5 \mathrm{~m}$ across finds close relatives in the billions of minute red coral polyps in a segment of tropical reef; the $2 \mathrm{~mm}$ copepod Calanus and other crustaceans are so numerous in the sea that they form a 'deep scattering layer' which reflects sonar signals as though it were the true bottom.

One receives a striking impression of overwhelming numbers and diversity, yet these aquatic animals share a number of common qualities. They breathe oxygen, usually extracted from the water; they appear to demand about the same nutritional requirements as do more familiar animals and ourselves; many capture their food by some form of filtration; being 'coldblooded', their metabolic activities vary with the temperature of their environment ; and most are inescapably at the mercy of a pervasive surrounding medium. However, despite their alien appearance, most of them have anatomical, physiological and biochemical features which relate them to our more usual idea of 'wildlife'.

\section{TOXICANTS}

The term 'toxicity' refers to the adverse effect of a chemical substance upon some living organism; the chemical is then called a 'toxicant'. Although the end-result of this adverse effect sometimes may be death, lethality is not a requirement of the intoxication process. In fact, many chemicals are harmful to aquatic animals without exhibiting the spectacular 'fish-kills' which often have received such wide publicity. However, Nature itself provides a continual toxic background of natural chemicals to which animals have had to accommodate throughout their evolution. The accumulation of persistent arsenic and mercury compounds in aquatic animals, their exposure to both surface and dispersed crude oil, and their development in the presence of an amazing variety of organic chemicals has extended over thousands of years. Even fresh water is very toxic to most marine animals; any substance or amount of a substance foreign to the normal environment - any xenobiotic - may become toxic.

People have manufactured and used chemicals for centuries, but recognition of, and concern over, possible toxic effects on wildlife are quite recent. Environmental persistence appears to arouse the greatest present concern, yet the persistent effluents of the Roman lead smelters, English felt works, German dye factories, and American tanneries of earlier eras undoubtedly were not beneficial to local aquatic fauna but failed to arouse much comment. Is today's situation really so much different? Basically, probably not; the mercurials, phenols and acids of another day certainly were as toxic to exposed wildlife then as they are now. However, an increase in their use by several thousand fold, distribution of those uses throughout the world, and addition of a growing complement of intentionally toxic chemicals 
DONALD G. CROSBY

such as the pesticides and disinfectants provide undeniable cause for concern (Table 2).

Table 2. Production of selected chemicals in the USA

\begin{tabular}{|c|c|c|}
\hline \multirow[t]{2}{*}{ Compoünd } & \multicolumn{2}{|c|}{ Annual production $\left(10^{6} \text { pounds }\right)^{a}$} \\
\hline & 1967 & 1971 \\
\hline Atrazine & - & $95^{\mathrm{b}}$ \\
\hline Chlorinated paraffins & 56.7 & 57.7 \\
\hline Cycloalkane insecticides ${ }^{\mathrm{c}}$ & 120.2 & 116.3 \\
\hline DDT & 103.4 & 59.3 \\
\hline$p$-Dichlorobenzene & 66.5 & 70.4 \\
\hline Diisodecyl phthalate & 123.1 & 135.7 \\
\hline Methylparathion & - & $51^{\mathrm{b}}$ \\
\hline Pentachlorophenol & 44.2 & 50.9 \\
\hline Tetrachloroethylene & 533.0 & 704.7 \\
\hline Trifluralin & - & $21^{\mathrm{b}}$ \\
\hline
\end{tabular}

a Source: US Tariff Commission.

b Approximate (R. von Rümker, personal communication, 1974).

- Aldrin, chlordane, dieldrin, endrin, heptachlor, chlorinated terpenes.

Recent pesticide recommendations repeatedly have stressed the desirability of non-persistent chemicals. However, lack of persistence does not automatically provide a benefit. All organic pesticides, as well as other chemicals, undergo transformations by environmental forces, at rates varying with environmental conditions. The transformation products may be either more or less toxic than the original to any particular animals. For example, the reaction of environmental pollutants with air and water, especially in the presence of sunlight, appears to be quite general ${ }^{3}$. Many substances-probably most - are degraded through a series of steps to less toxic products. 2,4-Dichlorophenoxyacetic (2,4-D)† decomposes to a polymeric humic acid ${ }^{4}$; the very toxic pentachlorophenol forms a mixture of substances which are of steadily decreasing toxicity to aquatic animals ${ }^{5}$; and such potentially dangerous insecticides as the pyrethrins ${ }^{6}$ and rotenone ${ }^{7}$ are so rapidly detoxified environmentally that they appear to constitute little hazard under normal use. The presence of photosensitizers often may

$\dagger$ Chemical names of pesticides and related compounds: aldrin. endo,exo-1,2.3.4.10.10hexachloro-1,4,4a,5,8,8a-hexahydro-1,4:5,8-dimethanonaphthalene; carbaryl, 1-naphthyl $N$-methylcarbamate; DBP, $p, p^{\prime}$-dichlorobenzophenone; DDD, 1,1-dichloro-2,2-bis( $p$-chlorophenyl)ethane; DDE, 1,1-dichloro-2,2-bis( $p$-chlorophenyl)ethylene; DDT, 1,1,1-trichloro2,2bis(p-chlorophenyl)ethane; dichlobenil, 2,6-dichlorobenzonitrile; dieldrin, endo,exo1,2,3,4,10,10-hexachloro-6,7-epoxy-1,4,4a,5,6,7,8,8a-octahydro-1,4:5,8-dimethanonaphthalene ; $S$-ethylparaoxon, $O, S$-diethyl $O$ - $p$-nitrophenyl phosphorothiolate; lindane, $\gamma$-isomer of 1,2,3,4,5,6-hexachlorocyclohexane; malathion, $O, O$-dimethyl $S$-(1,2-dicarbethoxyethyl) phosphorodithioate; methylparathion, $O, O$-dimethyl- $O$ - $p$-nitrophenyl phosphorothioate; monuron, 3-(p-chlorophenyl)-1,1-dimethylurea; paraoxon $O, O$-diethyl $O$ - $p$-nitrophenyl phosphate; parathion, $O, O$-diethyl $O$-p-nitrophenyl phosphorothioate; paraquat, $1,1^{\prime}$ dimethyl-4,4'-bipyridinium dichloride; photodieldrin, 1,1,2,3,3a,7a-hexachloro-5,6-epoxydecahydro-2,4,7-metheno- $1 \mathrm{H}$-cyclopenta[a]-pentalene; 2,4,5-T, 2,4,5-trichlorophenoxyacetic acid; toxaphene, chlorinated terpene mixture; trifluralin, $N, N$-dipropyl-2,6-dinitro- $\alpha, \alpha, \alpha-$ trifluoro-p-toluidine. 
be important $;$ DDT $^{8}, 2,4,5-\mathrm{T}^{9}$, and ethylenethiourea (ETU) ${ }^{10}$ are stable to photodecomposition alone but break down rapidly when sensitized.

However, a number of common pesticides and other substances can form breakdown products which are even more toxic than the original; aldrin is converted to dieldrin and then to the more poisonous photodieldrin ${ }^{11}$, and parathion forms paraoxon and $S$-ethyl paraoxon ${ }^{12}$. While the general course of these reactions is becoming more predictable, the possible toxic implications for aquatic animals so far is not ; carbaryl is converted environmentally to 1-naphthol which proved to be very toxic to oysters ${ }^{13}$, and the presumably stable polychlorinated biphenyls (PCBs) are reduced to less persistent homologues ${ }^{14,15}$ and hydroxylated to more toxic derivatives ${ }^{16}$.

Pesticides (and other chemicals) also can be transformed by living plants, animals and microorganisms, sometimes with surprising results. Degradative metabolic reactions generally represent oxidation, reduction, hydrolysis and dehydrochlorination, and the products then may be converted further to water-soluble sugar and amino acid conjugates. In addition, microorganisms often can bring about unexpected and important changes. For example, the presumed persistence of DDD in Clear Lake, California, has become almost an ecological classic ${ }^{17}$. However, Miskus et al. ${ }^{18}$ demonstrated that the microflora of Clear Lake rapidly and continuously reduced the DDT which was used in surrounding pear orchards to DDD to provide a constant supply; the original DDD could long-since have disappeared. The startling decline of DDD residues in the eggs of grebes from that region ${ }^{19}$ might reasonably be attributed to reduced use of the DDT rather than a new food source. Even the acute toxicity of DDT 'detoxication' products to aquatic species is not predictable from mammalian data; at 20 p.p.b. (p.p. $10^{9}$ ), DBP is as toxic as DDT to brine shrimp (Artemia salina), while DDD is about four times more toxic ${ }^{20}$. Effects of the unexpected DDT metabolites 2,2-bis( $p$-chlorophenyl)ethanol ${ }^{21}$ and 2,2-bis(p-chlorophenyl) acetonitrile $^{22}$ have not even been reported.

In recent years, the toxicological significance of byproducts and impurities resulting from pesticide manufacture and use has assumed considerable importance. The environmental detection of chlorinated dioxins in phenol derivatives, ETU in common fungicides, hexachlorobenzene in the herbicide dacthal, vinyl chloride used as an aerosol propellant, and the widelydistributed PCBs and their relatives has brought the realization that our particular concern over pesticides actually may only be because we are relatively so familiar with them. When we consider how very little is understood about the thousands of coexisting transformation products, impurities and non-pesticide industrial chemicals which can reach aquatic ecosystems, the number and diversity of possible toxicants again is staggering.

\section{EFFECTS}

The acute toxic effects of pesticides on aquatic animals, typified by socalled 'fish-kills', certainly are the most obvious and have been the most widely publicized. As shown in Table 3, aquatic species often are especially sensitive, and, in fact, have received extensive use in assays for toxicants. Typical criticisms against many of these data are that:(1) tests often have been 
conducted with toxicant suspensions-where aqueous solubility limits have been exceeded, variable exposure routes and effective concentrations can result; (2) temperatures seldom have been adequately controlled, although the toxicity of pesticides to Daphnia, for example, can increase 100-fold with a rise of $4^{\circ} \mathrm{C}^{23} ;(3)$ other important parameters such as salinity, oxygenation and method of dosing seldom are specified; and (4) test conditions usually are so artificial as to preclude clear extension to the real environment. For example, while trifluralin is recognized as extremely toxic to fish in static tests, prior adsorption into soil-for which the herbicide has great affinity-resulted in a 227 -fold reduction in the median lethal concentration $\left(\mathrm{LC}_{50}\right)^{26}$.

Table 3. Acute toxicity ${ }^{\mathrm{a}}$ of pesticides to selected aquatic animals

\begin{tabular}{|c|c|c|c|c|c|}
\hline \multirow[b]{2}{*}{ Compound } & \multicolumn{5}{|c|}{$\mathrm{LC}_{50}(\mu \mathrm{g} / 1)^{23-25}$} \\
\hline & $\begin{array}{c}\text { Water flea } \\
\text { (Daphnia magna) } \\
21^{\circ}, 48 \mathrm{~h}\end{array}$ & $\begin{array}{c}\text { Scud } \\
\text { (Gammarus } \\
\text { fasciatus) } \\
15.5^{\circ}, 48 \mathrm{~h}\end{array}$ & $\begin{array}{l}\text { Sand shrimp } \\
\text { (Crangon } \\
\text { septemspinosa) } \\
20^{\circ}, 48 \mathrm{~h}\end{array}$ & $\begin{array}{c}\text { Hermit crab } \\
\text { (Pagurus } \\
\text { longicarpus) } \\
20^{\circ}, 48 \mathrm{~h}\end{array}$ & $\begin{array}{c}\text { Bluegill } \\
\text { (Lepomis } \\
\text { macrochirus) } \\
24^{\circ}, 96 \mathrm{~h}\end{array}$ \\
\hline Parathion & 0.8 & $6^{\mathrm{b}}$ & & & 95 \\
\hline Malathion & 0.9 & $1.8^{\mathrm{b}}$ & 210 & 100 & 90 \\
\hline Methylparathion & 4.8 & 6 & 3 & 7 & 5720 \\
\hline DDT & 5.5 & 3.6 & 1 & 1 & 8 \\
\hline Dieldrin & 145 & $1000^{\mathrm{b}}$ & 10 & 51 & 7.9 \\
\hline Trifluralin & 560 & 1800 & & & $68^{c}$ \\
\hline Lindane & 1900 & $88^{b}$ & 5 & 11 & 51 \\
\hline Dichlobenil & 10000 & 5900 & & & $1100^{c}$ \\
\hline 2,4-D & $>100000$ & 3200 & & & $8000^{c}$ \\
\hline
\end{tabular}

- $\mathrm{LC}_{50}$ denotes median lethal concentration. $\quad{ }^{\mathrm{b}} \mathrm{G}$. lacustris $\quad$ c 48 hours.

All together, fewer than 20 aquatic species have received more than cursory examination for the acute effects of pesticides, and almost no information exists on the effects on juvenile stages, toxicity during moulting, etc. Actually, true death often is difficult to determine in invertebrates such as Daphnia; all vital signs cease until the animal is removed from contact with the toxicant. An individual often can absorb relatively enormous amounts of pesticide without apparent harm as long as the external level remains low.

Despite their sensitivity, most aquatic species indeed are seldom exposed to lethal pesticide levels. However, fragmentary but illustrative examples of undesirable chronic effects underscore other hazards to which they may be subjected (Table 4). Numerous further examples have been discussed elsewhere ${ }^{33}$, but it is apparent that no consistent body of knowledge presently exists from which to make accurate, detailed predictions about harmful - or tolerated-levels of pesticides, impurities and transformation products.

\section{EXPOSURE}

The first requirement of intoxication is exposure. Despite the number and complexity of environmental chemicals on the one hand and wildlife 
Table 4. Some chronic effects of pesticides in aquatic invertebrates

\begin{tabular}{|c|c|c|}
\hline $\begin{array}{l}\text { Compound } \\
\text { (Concentration) }\end{array}$ & Organism & Effect (Ref.) \\
\hline DDT $(7 \mu \mathrm{g} / \mathrm{l})$ & C. virginica & $50 \%$ decrease in shell growth \\
\hline Parathion $(850 \mu \mathrm{g} / \mathrm{l})$ & (Oyster) & after $96 \mathrm{~h}$ exposure 27 \\
\hline DDT $(10 \mathrm{mg} / \mathrm{kg})$ & $\begin{array}{l}\text { Uca pugnax } \\
\text { (Crab) }\end{array}$ & $\begin{array}{l}\text { Loss of coordination and } \\
\text { equilibrium }{ }^{28} \text {. }\end{array}$ \\
\hline Carbaryl (1 mg/l) & $\begin{array}{l}\text { Cancer magister } \\
\text { (Crab) }\end{array}$ & $\begin{array}{l}\text { Moulting of prezoeae to zoeae } \\
\text { prevented (delayed at } 0 \cdot 1 \mu \mathrm{g} / \mathrm{l} \text {. No } \\
\text { survival after } 25 \text { days at } 10 \mu \mathrm{g} / \mathrm{l}^{25}\end{array}$ \\
\hline DDT $(50 \mu \mathrm{g} / \mathrm{l})$ & $\begin{array}{l}\text { C. virginica } \\
\text { (Oyster) }\end{array}$ & $\begin{array}{l}90 \% \text { larval death within } 14 \text { days; } \\
\text { exposure on shell bed }{ }^{29} \text {. }\end{array}$ \\
\hline DDT & $\begin{array}{l}\text { Elminius modestus } \\
\text { (Barnacle) }\end{array}$ & $\begin{array}{l}\text { Barnacle larvae will not become } \\
\text { attached }^{30} \text {. }\end{array}$ \\
\hline $\begin{array}{l}\text { DDT } \\
\text { Methylparathion }\end{array}$ & $\begin{array}{l}\text { Palaemonetes kadiakenesis } \\
\text { (shrimp) and }\end{array}$ & Development of resistance ${ }^{31,32}$ \\
\hline Toxaphene & $\begin{array}{l}\text { Procambarus acutus } \\
\text { (crayfish) }\end{array}$ & \\
\hline
\end{tabular}

species on the other, substantial contact between the two is necessary for any effect. Exposure depends largely upon the physical properties of the xenobiotic and the peculiar habits of the animal.

\section{Particulate matter}

The more stable xenobiotics seldom are found in pure chemical form in the environment; in the aquatic world, they most often exist adsorbed to particles of suspended silt $^{34}$, bottom mud or detritus ${ }^{28}$, as constituents of thin surface films ${ }^{35}$, or within the biological matter used as food ${ }^{33}$. Thus, exposure of animals could subsequently occur through external contact (e.g. with a film) or by ingestion of contaminated particulate matter. The hydrophobic chlorinated hydrocarbons, especially, become strongly associated with lipoidal surfaces, the organic compounds of soil, and the detritus from decaying plants and animals ${ }^{36}$, although other chemicals share this trait to an extent depending upon their polarity and other properties. The adsorbed or dissolved compounds can be bound tenaciously ${ }^{37}$, and their partition coefficient with respect to water $\left(K_{\mathrm{om}}\right.$ or $\left.K_{\mathrm{d}}\right)$ may exceed $10^{5}$. Consequently, pesticides often are found in largest quantity in the sediments that accompany major food sources for bottom-dwellers or in the suspended matter ingested by filter-feeders. While perhaps a major proportion of the DDT in off-shore waters is attached to particles less than $2 \mu \mathrm{m}$ in diameter and so generally not removed by filter-feeders ${ }^{34}$, the principal amount in estuarine situations is associated with particles in the $50-1000 \mu \mathrm{m}$ ingested range ${ }^{28}$.

This affinity of many stable chemicals for surfaces inevitably leads to a concentrating effect, sometimes to an extent of more than 10000-fold in living and even dead particulates ${ }^{38,39}$. Pesticide residue measurements in selected organisms increasingly higher in food chains occasionally show further incremental increases leading to the attractive and now widespread 
concept of 'food-chain biomagnification' ${ }^{\mathbf{2} 0-43}$. Absorption from the gut can be quite efficient and may involve direct transfer of the chemical, from food to host, as a lipid solution ${ }^{44}$. These features have supported the frequent conclusion that the primary route of uptake and transport of pesticides is through the food ${ }^{1,41-43,45}$.

\section{Solutions}

Of course, pesticides and other xenobiotics also are found in water itself. Although environmental concentrations generally are extremely small (parts per $10^{12}$ ) except in the immediate area of a direct introduction, even the most hydrophobic compounds exhibit measurable aqueous solubility (Table 5). Accurate solubility determinations for such compounds are difficult, and some - such as those for DDT-perhaps represent only degrees of dispersion of small aggregates. For example, the 'solubility' of DDT was reduced from 25 to $6 \mu \mathrm{g} / 1$ when the $5 \mu \mathrm{m}$ particle size was lowered tenfold and further reduced to $1.7 \mu \mathrm{g} / 1$ by high-speed centrifugation ${ }^{49}$, so the wide variation among solubility data seen in the literature is not surprising. Further, DDT may be solubilized strongly by natural substances ${ }^{50,51}$, so that extension of the laboratory data to environmental situations is questionable. Levels of extractable pesticides in natural waters lie far below saturation but often are remarkably constant, e.g. $2.3-2.7 \mathrm{ng} / 1$ of DDT in Northern US Coastal Water ${ }^{34}$ or $750 \mathrm{ng} / 1$ in a Canadian forest stream system $^{52}$, suggesting that the pesticide indeed may exist in equilbrium with the large sediment reservoir.

Although the relative importance of ingested particulates versus direct uptake from water for exposure to toxicants has been resolved in only a few cases and undoubtedly varies with species and circumstances, a growing body of evidence suggests that direct exposure is much more extensive and significant than might be predicted. A mature ( 20 gram) oyster (Crassostrea virginica) can transport as much as $24 \mathrm{l} / \mathrm{h}$ of water for feeding and respiration $^{53}$, a mussel community (bed) may transport 22 million metric tons of water annually ${ }^{54}$, and even a minute zooplankton crustacean such as

Table 5. Aqueous solubility of hydrophobic xenobiotics

\begin{tabular}{|c|c|c|c|}
\hline Compound & $\begin{array}{l}\text { Satura } \\
\mathrm{mg} / \mathrm{l}\end{array}$ & $\begin{array}{c}\text { bility }\left(20-25^{\circ}\right) \\
\mu \mathrm{M}\end{array}$ & Ref \\
\hline DDT & 0.0012 & 0.0034 & 46 \\
\hline Aldrin & 0.027 & 0.074 & 47 \\
\hline Trifluralin & 0.050 & 0.15 & 26 \\
\hline DDE & $<0.12$ & $<0.34$ & 47 \\
\hline Dieldrin & 0.19 & 0.48 & 48 \\
\hline Toxaphene & 0.40 & $0.97^{\mathrm{a}}$ & 47 \\
\hline Lindane & 0.60 & 2 & 47 \\
\hline Parathion & 20 & 69 & 47 \\
\hline Pentachlorophenol & 20 & 75 & 47 \\
\hline$p$-Dichlorobenzene & 80 & 540 & 47 \\
\hline
\end{tabular}

- Based on average mol. wt of $\mathbf{4 1 3}$. 
Daphnia can circulate almost $100 \mathrm{ml} / \mathrm{day}^{55}$. At half this rate, a $10 \mu \mathrm{g}$ daphnid would be exposed daily to 50 p.p.m. of its body weight if the xenobiotic concentration in the water were $10 \mathrm{ng} / 1$ (10 p.p. $\left.10^{12}\right)$, clearly enough to afford high residues of stable substances.

Respiration in zooplankton ${ }^{56}$, including both microcrustaceans ${ }^{57,58}$ and the larval forms of other organisms ${ }^{57,59}$, appears to be largely through the outer integument in contact with the animal's environment; pesticide uptake is active and direct, although dead animals and phytoplankton on which live animals graze also can passively accumulate high pesticide levels from the water ${ }^{38,60}$. Direct DDT uptake by the gills in larger forms of aquatic bivalves ${ }^{61}$, crayfish $^{57}$, freshwater prawns ${ }^{57}$, shrimp $^{44}$, and fish ${ }^{56,62,63}$ now has been shown clearly to be the primary route by controlled laboratory experiments, with ingestion of secondary importance and absorption through the integument negligible.

Toxicants also are returned to water efficiently by diffusion (from integument or gills) and by active excretion in urine or faeces ${ }^{44,61,64-69}$. The removal can be quite rapid; oysters and clams which had accumulated DDT from the surrounding medium lost as much as 90 per cent of it within seven days once they were returned to DDT-free water ${ }^{68}$. This exchange eventually results in the establishment of a residue plateau in the presence of a constant reservoir of toxicant ${ }^{57,59,65,70}$; the rate of approach generally exceeds the rate of loss, and both diminish with increasing body weight ${ }^{44}$.

Aquatic organisms also can be exposed to metabolites and other pesticide transformation products. However, the concentrations of these substances generally are very small at any given time and they tend to be increasingly polar as degradation proceeds. Several exceptions are important: (1) conversion to stable, lipid-soluble products; (2) conversion to much more toxic products; and (3) circumstances of limited dilution. For example, DDT commonly is converted to DDD and DDE by lower animals and phytoplankton $^{57,71}$, and these lipid-soluble metabolites remain in the organism along with the parent compound. Furthermore, the released DDE is more rapidly absorbed from salt water than is DDT ${ }^{72}$. While DDD and DDE appear somewhat less toxic than DDT, aldrin is epoxidized to stable, lipid-soluble, and more toxic dieldrin ${ }^{58}$. As such metabolites are excreted by a large or insensitive animal, perhaps as a form of detoxication, they then become available in water or particulate matter to expose more sensitive species unless rapidly dispersed and diluted.

\section{POSSIBLE GENERALITIES AND SIMPLIFICATION}

When we consider the number of chemicals to which aquatic animals are exposed, the possible environmental transformation products, the number and diversity of living species, and the ways in which toxicants and biota could interact, the impression is one of paralysing complexity. Moreover, the annual increase in the production of most chemicals (Table 2) serves to compress the timeframe available for acquiring meaningful information about their ecological effects, and the bulk of past research seemingly has done little more than repeatedly suggest the unusual sensitivity of the aquatic environment. 
Still, under the pressing restrictions of time and human needs, generalizations assume major importance. For example, both logic and past experience dictate restriction of the environmental release of substances which move and concentrate or form transformation products which do. However, it also is patently unreasonable to expect that society will restrict the use of thousands of major industrial chemicals until extensive, worldwide ecological tests can reveal which of them present cause for concern. Clearly, the guidance of further generalities is needed.

\section{Bioconcentration}

While the transport and intercompartment transfer of pesticides in air, water, and soil unquestionably are important, principal concern must be reserved for the tendency of a substance to distribute and concentrate in biota - the bioconcentration potential ${ }^{73,74}$-and its consequences. Because of their basic ecological importance, aquatic communities are of particular interest, but the experimental determination of bioconcentration potential for all chemicals and all aquatic species again is obviously impractical.

Many-perhaps most-aquatic invertebrates and vertebrates store persistent organic compounds in their oily fat, often concentrated in the liver or equivalent hepatopancreas ${ }^{62,71}$. The rapid absorption of such compounds through the gill surface and frequent ease of release to the surrounding water suggests the existence of a facile equilibrium between the stored chemical and the outside medium. As a first approximation, the bioconcentration potential of many xenobiotics in aquatic animals might be reflected in their oil/water partition coefficients (Table 6). In this case, $p$-values ${ }^{75}$ only provide indications of high coefficients; saturation-solubility ratios offer a further approximation, but the actual coefficients-although seldom

Table 6. Partition values for four chlorinated insecticides

\begin{tabular}{|c|c|c|c|c|c|}
\hline Compound & $p$-value & $\begin{array}{l}\text { Saturation } \\
\text { solubility }^{\text {ratio }^{\mathrm{b}}}\end{array}$ & $\begin{array}{l}\text { Partition } \\
\text { coefficient }^{\mathrm{c}} \\
\left(K_{p}\right)\end{array}$ & $\begin{array}{l}\text { Observed } \\
\text { bioconcentration } \\
\text { factor }^{d}\end{array}$ & Examples \\
\hline DDT & 0.93 & $10^{8}$ & $9.1 \times 10^{4}$ & $9 \times 10^{4}$ & 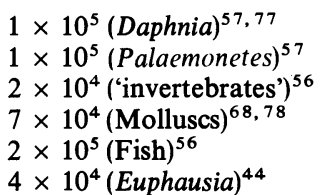 \\
\hline Aldrin & 0.98 & $3 \times 10^{7}$ & $1.0 \times 10^{5}$ & $1 \times 10^{5}$ & $\begin{array}{l}1.4 \times 10^{5}(\text { Daphnia })^{57} \\
10^{5}{\text { (Chlamydotheca })^{69}}^{-1}\end{array}$ \\
\hline Dieldrin & 0.88 & $2 \times 10^{5}$ & $3.6 \times 10^{4}$ & $3 \times 10^{4}$ & $\begin{array}{l}5 \times 10^{4}{\text { (Chlamydotheca })^{69}} \\
1 \times 10^{4}{\text { (Fish })^{64}}^{4} \times 10^{3}{\text { (Mollusc })^{78}}^{(2)}\end{array}$ \\
\hline Lindane & 0.78 & $5 \times 10^{3}$ & $1.7 \times 10^{3}$ & $1 \times 10^{2}$ & $1 \times 10^{2}{\text { (Fish })^{64}}^{2}$ \\
\hline
\end{tabular}

\footnotetext{
- Isooctane $/ 80 \%$ acetone. $25.5 \mathrm{C}^{73}$.

b Based on solubility in vegetable or petroleum oil.

c Hexane/water ${ }^{74}$.

d Average value based on fresh weight.
} 
available-provide the best estimate. Even so, the values of Voerman ${ }^{76}$ are based on hexane rather than fat or oil in which DDT, for example, is about twice as soluble ${ }^{73}$.

This partition model considers bioconcentration in an organism to be a liquid-liquid extraction of the aqueous medium by some volume of immiscible fatty solvent. However, unlike most laboratory extractions, the aqueous phase may be represented as an infinite supply of xenobiotic at some (usually) low but rather constant level. Given time for equilibration, the exact volume of fat is theoretically immaterial; given a fixed chemical potential (fugacity) and an infinite supply of solute in the water, the fat concentration must remain constant. Unfortunately, few residue analyses have been reported on a lipid basis, although the total residue will increase with increasing amounts of fat. The average proportion of fat varies considerably between species (Table 7) ${ }^{79}$, individuals ${ }^{80}$, development stage ${ }^{81}$, and season $^{80}$.

Table 7. Fat content of some aquatic animals

\begin{tabular}{llll}
\hline \multicolumn{1}{c}{ Common name } & \multicolumn{1}{c}{ Species } & \% Fat ${ }^{\text {ab }}$ & Ref. \\
\hline 'Plankton' & Eucalanus sp. & 34 & 83 \\
& Gaussia princeps & 28.9 & 83 \\
Krill & Calanus helgolandicus & 15 & 83 \\
& Euphausia superba & 4.55 & 80 \\
Pacific halibut & Euphausia pacifica & 2.9 & 80 \\
Blue crab & Hippoglossus stenolepsis & 1.22 & 79 \\
Catfish & Callinectes sapidus & 1.02 & 79 \\
Spiny lobster & Ictalurus punctatus & 0.96 & 79 \\
White shrimp & Panulirus argus & 0.33 & 79 \\
Brown shrimp & Penaeus setiferus & 0.20 & 79 \\
Iceland cod & Penaeus aztecus & 0.14 & 79 \\
\hline
\end{tabular}

- Total ether extractables. ' 'Edible portion' in most cases

Typically, the oils contain relatively high proportions of unsaturated glycerides and varying but major levels of saturated esters, sterols and phospholipids ${ }^{80-83}$. While solubilities might be expected to reflect differences in fat composition, there is a surprising constancy in the saturation solubility of DDT in a variety of natural oils (about ten per cent by weight) ${ }^{73}$; values for residues in natural biota generally are about $10^{-3}$ to $10^{-4}$ of this level. While saturation solubilities are strongly affected by temperature ${ }^{47}$, the influence at this degree of dilution is questionable except in the unlikely event of drastically different temperature coefficients for water and fat solubilities.

However, metabolism and other reactions can be expected to bring about major changes in the xenobiotic constituents of fats. For example, while adequate aqueous solubilities or partition coefficients have not been published for DDE and DDD, $p$-values in six solvent systems ${ }^{75}$ uniformly show DDE to favour the non-polar phase and DDD the polar phase, compared to DDT; as metabolism progressed, one might predict increasing 
proportions of DDE accompanied by decreasing levels of DDD in body fat. On the other hand, while the solubilities of methylmercuric salts would lead one to expect a low bioconcentration potential, reaction with or binding to internal sites requires that a new partition be invoked-one which considerably favours retention. Each metabolite represents a distinct and separate system.

Unfortunately, further verification and extension of the relationship between partition coefficients is not presently possible. Despite extensive partition ratio measurements by Hansch ${ }^{84}$ and others, a general lack of $K_{p}$ values exists. Despite the availability of simple experimental methods, even fewer data on bioconcentration factors against a constant pesticide concentration have been published, and almost none of these consider fat content.

\section{Hazardous substances}

A chemical released into water will distribute itself into other environmental compartments - sediment, air and biota - to a degree indicated by its partition coefficient between soil organic matter and water $\left(K_{\mathrm{om}}\right)^{37,77}$, the partition coefficient between lipid (non-polar solvent) and the aqueous medium $\left(K_{p}\right)^{74}$ and the time $\left(t_{\frac{1}{2}}\right)$ required for 50 per cent to evaporate ('codistil') $)^{85}$.

If we accept that the principal interface between toxicants and lower aquatic animals is through direct exposure in the water, then $1 / K_{\text {om }}$ reflects the tendency of the compound to be withdrawn from water by adsorption, an equilibrium which probably represents the major control over xerobiotic concentrations. Although values calculated for $t_{\frac{1}{2}}$ often are surprisingly low ${ }^{85}$, they may not be meaningful to the present argument because of the frequent presence of surface films, return to water by precipitation, and evaporation from an essentially infinite reservoir of compound at constant concentration. However, breakdown (transformation) of the substance in the aquatic environment by both biological and non-biological means does provide an avenue for loss; as photodecomposition in sunlight and primary metabolism often "provide identical products, the proportion of starting material $\left(R_{48}\right)$ remaining after 48 hours exposure in water or aqueous alcohol to $>300 \mathrm{~nm}$ ultra-violet light could provide a measure of the chemical stability ${ }^{3}$.

Apparently, the lipid-water partition coefficient provides an estimate of bioconcentration potential as well as an indication of the abstraction of the substance from water by aquatic biota; in fact, $K_{p}$ and $K_{\text {om }}$ often are remarkably similar ${ }^{77}$. However, $p$-value-the proportion of a compound in an organic phase (such as isooctane or hexane) in equilibrium with an aqueous phase $^{73}$ - can provide a much more convenient representation of bioconcentration potential in this case. Acute toxicity, too, is an important measure of environmental hazard, and the reciprocal median immobilization concentration $\left(1 / I C_{50}\right)$ for the common microcrustacean, Daphnia magna, offers a directly proportional indicator ${ }^{23}$.

Table 8 lists estimates of these factors for several illustrative pesticides. It is apparent that their product could provide an estimate of potential 
hazard $(H)$ to aquatic environments

$$
H=P R /\left(K_{\mathrm{om}}\right)\left(I_{50}\right)
$$

The factors are expressed so that low values are an indication of relative safety, but it is doubtful that any would ever reach zero; some finite estimate should be provided, however low. $K_{\mathrm{om}}$ or related soil/water partition coefficients could be standardized on purified humic acid ${ }^{36}$; to avoid solubility problems, $p$-values for isooctane- $80 \%$ aqueous acetone are convenient ${ }^{75} ; R$ is conveniently measured with starting concentrations of about $10^{-4} \mathrm{M}^{86}$; and $I C_{50}$ likewise should be in molar terms ${ }^{23}$. The variability observed in these values suggests that realistic approximations would be adequate.

Table 8. Estimation of relative hazard $(H)$

\begin{tabular}{lcccccc}
\hline \multicolumn{1}{r}{ Measure } & Parathion & DDT & Trifluralin & Lindane & $2,4-\mathrm{D}$ & Paraquat \\
\hline $1 / K_{\mathrm{om}}$ & $10^{-4}$ & $10^{-5}$ & $5 \times 10^{-3}$ & $10^{-3}$ & $5 \times 10^{-2}$ & $10^{-4}$ \\
$P$ & 0.76 & 0.93 & 0.93 & 0.78 & 0.16 & 0.01 \\
$R_{48}$ & 0.5 & 1.0 & 0.1 & 0.9 & 0.8 & 0.9 \\
$1 / I C_{50}(\mathrm{M})$ & $3.7 \times 10^{8}$ & $6.7 \times 10^{7}$ & $6 \times 10^{5}$ & $1.5 \times 10^{5}$ & $1 \times 10^{3}$ & $2.4 \times 10^{4}$ \\
$H$ & 14000 & 620 & 280 & 105 & 6.5 & 0.22 \\
\hline
\end{tabular}

As expected, the calculation shows that DDT presents a problem for aquatic animals and 2,4-D does not. Although paraquat salts have very high $K_{\mathrm{om}}$ and $R$ values, the almost complete lack of lipid-water partition and moderate toxicity combine to greatly reduce hazard. Lindane $(\gamma$-BHC) looks better than might have been expected, due in part to a low $K_{\mathrm{om}}$, but parathion and trifluralin bear further attention.

Such a measure of hazard undoubtedly can be refined, or presented as a set of scales as Goring ${ }^{77}$ has done. It probably has no absolute meaning, and certainly is not intended to provide any precise model of the aquatic environment. However, the partition coefficients $p$ and $K_{\mathrm{om}}$ are easy to obtain and standardize; culture and tests with Daphnia species are wellknown and reproducible; and photolysis in water followed by analysis for starting material is simple. Interpretation of $H$ may be more difficult, although the factors in Table 8 suggest that $H$-values exceeding about 100 should constitute grounds for careful scrutiny.

To test these concepts, values for the non-polar aquatic herbicide dichlobenil (2,6-dichlorobenzonitrile) were estimated (Table 9). The results suggest that while this compound has a rather low toxicity to aquatic life, its lack of adsorbability would allow it to remain relatively available. It is fairly persistent in water but is not highly bioconcentrated. In fact, the calculated bioconcentration potential $\left(K_{p}\right)$ conforms to those actually observed in field trials with both fish $(c a .50)^{88}$ and invertebrates $(c a .70)^{89}$. The $H$-value places it close to lindane; in instances where lindane might cause concern, dichlobenil, too, should be examined despite its history of relative safety. 
DONALD G. CROSBY

Table 9. Estimation of dichlobenil hazard $(H)$

\begin{tabular}{lcr}
\hline Factor & Dichlobenil & \multicolumn{1}{c}{ Ref. } \\
\hline $1 / K_{\text {om }}$ & 0.01 & 77 \\
$P$ & 0.60 & 46 \\
$R_{48}$ & 0.9 & $\mathrm{a}$ \\
$1 / I C_{50}$ & $1.8 \times 10^{4}$ & 23,24 \\
$K_{p}$ & $100^{\mathrm{b}}$ & 86 \\
$H$ & 97 & \\
\hline \multicolumn{2}{c}{.} \\
: Estimate. & & \\
b Hexane/water. & &
\end{tabular}

\section{Metabolites}

Despite the considerable volume of research on pesticide metabolites, remarkably little is known about the products, processes and rates to be expected in aquatic animals. Rodents have provided most of the existing metabolism data, and comparative results from the lower animals generally have come from isolated tissues and organs. However, the pioneering work of B. B. Brodie ${ }^{90}$, J. N. Smith ${ }^{91}$, L. C. Terriere ${ }^{92}$, and others leads to the conclusion that the lower animals are limited in the rates and pathways by which they metabolize xenobiotics.

In vitro observations led to the attractive proposal that aquatic organisms do not require the metabolic (detoxifying) capacity of the terrestrial animals because they can excrete xenobiotics directly into what is, for practical purposes, an infinite volume of diluent. For example, the generalized oxidizing ability of liver microsomal preparations indicated fish to be less than 20 per cent as effective as mammals, and they seemed completely unable to reduce nitro or azo groups ${ }^{92}$. However, practical experience with intact, live animals, shows that aquatic species oxidize alkrin to dieldrin ${ }^{57}$ and pentachlorophenol to a quinone ${ }^{93}$, reduce DDT to $\mathrm{DDD}^{57}$, and dehydrochlorinate DDT to $\mathrm{DDE}^{57}$. The wide variety of metabolic reactions carried out by terrestrial insects provides a suspicion that their aquatic relations also might be more capable than we imagine, and there is little reason to believe that metabolism would be restricted to a 'liver', especially in the relatively uncomplicated aquatic forms.

Pesticide metabolites from living mammals and birds usually are isolated from excretion products. Analogous procedures have not been applied to aquatic invertebrates, in part because of the small size of many animals and the difficulty in isolating extremely minute amounts of soluble metabolites from large volumes of water. We have successfully applied the controlledtemperature metabolism chamber shown in Figure 1; the animals are dosed in a separate container with either cold or radiolabelled compound, transferred live to the chamber, and held in a slow continuous steam of water. Solid wastes are separated in a trap, and the dissolved substances are collected quantitatively on non-ionic macroreticular resins such as the Rohm and Haas Company XAD resins, subsequently eluted with methanol, and subjected to thin-layer chromatography (TLC). Identity can be established by gas chromatography with element-specific or mass spectrometer detec- 
tors, and quantitation is achieved by appropriate counting methods. Patterns displayed upon two-dimensional TLC plates are compared with 'metabolic maps' prepared from known standards, permitting rapid and simple verification of metabolic pathways.

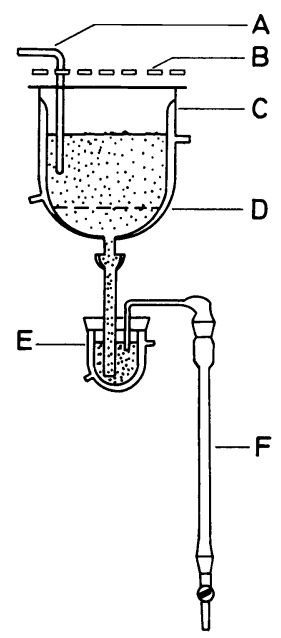

Figure 1. Aquatic metabolism chamber, including water inlet (A), perforated cover(B), jacketed chamber $(\mathrm{C})$, restraining screen $(\mathrm{D})$, cold trap for solids $(\mathrm{E})$, and adsorbent column $(\mathrm{F})$

To illustrate the utility of the technique, the metabolism of DDT in the marine-boring 'gribble' (Limnoria tripunctata) was examined. Two hundred adult animals about $2.0 \mathrm{~mm}$ in length were allowed to ingest cellulose powder treated with ${ }^{14} \mathrm{C}$-DDT, held in a small version of the metabolism chamber, and metabolites were collected over a period of three days. Analysis suggested that dehydrochlorination was not a major route of detoxication but that DDD and DDA were excreted. The presence of DDA would imply that a strictly aquatic arthropod can detoxify a fat-soluble toxicant by conversion to a water-soluble metabolite, and that in so doing, it behaves according to what is expected of a 'terrestrial' animal while most of its insect relatives apparently do not. In fact, the coelentrate sea-anemone Anthopleura xanthogrammica efficiently converts water-soluble $p$-chloroaniline to 'fat-soluble' $p$-chloroacetanilide [as do young salmon (Onchorhyncus tshawytsche) and aquatic frogs (Xenopus laevus)]. Such results certainly do not deny the value of in vitro study of the comparative enzymology of xenobiotic metabolism but stress the added importance of investigating overall detoxication and activation processes and the substances which intact, unstressed animals concentrate or release to their environment. They also can provide an eventual basis for predicting those types of chemicals likely to be most toxic at a particular level of phylogeny.

There has been some success in simulating metabolic processes in vitro. Although both the free-radical generating Fenton's reagent, the probably 
ionic peroxytrifluoroacetic acid, and other systems have been employed to simulate oxidative metabolism ${ }^{94}$, the most remarkably general results have been achieved by irradiation of an aqueous solution of the pesticide with ultra-violet light at wavelengths greater than $300 \mathrm{~nm}^{85}$. The products of oxidation, reduction, hydrolysis and elimination so produced often are qualitatively identical to those of metabolism ${ }^{95}$, obviously exclusive of the conjugates - such as glucuronides-formed by secondary metabolism. Again to cite only a single example, Table 10 shows the close relationship of the

Table 10. Photolysis and metabolism of monuron

\begin{tabular}{lcc}
\hline \multicolumn{1}{c}{ Compound } & Photoproduct $^{96}$ & $\begin{array}{c}\text { Metabolite }^{97} \\
\text { (Rat) }\end{array}$ \\
\hline 3-(p-Chlorophenyl)-1-formyl-1-methylurea & + & \\
3-(p-Chlorophenyl)-1-methylurea & + & + \\
1-(p-Chlorophenyl)urea & + & + \\
3-(4'-Chloro-2'-hydroxy)-1,1-dimethylurea & + & + \\
3-(4'-Chloro-2'-hydroxy)-1-methylurea & \pm & + \\
3-(4'-Chloro-2'-hydroxy)urea & \pm & + \\
3-(4'-Chloro-3'-hydroxy)urea & & + \\
\hline
\end{tabular}

primary metabolites of the herbicide monuron [3-(p-chlorophenyl-1,1-dimethylurea] to the products of its photodecomposition in water. While the mechanisms of these photochemical reactions have not been clearly elucidated, and the relationship to the metabolites formed by aquatic invertebrates under similar circumstances still remains obscure, each process must reflect stable and inherent chemical traits of both xenobiotic and organism. As knowledge of such relationships develops and methods are standardized, the relatively simple prediction, preparation and identification of large amounts of candidate metabolites in this way could provide another valuable generalization.

\section{CONCLUSIONS}

The toxicant-wildlife complex seems almost infinitely variable, even when viewed through only this single fragment. Chemicals probably have accumulated and cycled in the aquatic environment over the ages - mercury and arsenic compounds, petroleum hydrocarbons, waxes and pristane among them-but -the facile detection of chlorinated hydrocarbons in aquatic biota emphasizes that substances exhibiting a dangerous degree of toxicity can accumulate and spread. However, despite the complexity, both toxicants and biota must conform to basic chemical principles. With due regard for biological inconsistencies-indeed because of them-the discovery of simplifying generalities to explain the environmental behaviour of chemicals has become imperative, especially for proper regulatory control.

Obviously, simplification is possible. However, attempts to use mathematical models so far have been only partially successful ${ }^{35,98,99}$; for example, the model developed by Kerr and Vass ${ }^{35}$ relies largely on the important 
measures of filtration rate and metabolism rate based on oxygen uptake, both of which prove to be outrageously inconsistent. Even so, the importance of direct uptake of a compound from water and a continual elimination from the organism are clearly indicated. Actual equilibration is denied.

The alternate notion that bioconcentration might reflect primarily a partition (equilibrium) process leads to certain interesting corollaries and consequences:

(1) Given a constant reservoir and time for equilibration, the maximum xenobiotic concentration in fat is fixed; however, residue level would be expected to vary with the fat content of the individual organism and could change periodically. A reduction in the fat volume would not lead to increased xenobiotic concentration in the animal.

(2) Each metabolite will exhibit its own partition characteristics separate from those of the parent compound. Therefore, metabolism would not be expected to reduce the concentration of the original substance in the presence of a constant external reservoir (the water), although locally the proportions of a stable metabolite might change with changing environmental levels and with peculiarities of transport within the organism.

(3) No matter whether the residue level in water is measurable or not, the presence of a stable xenobiotic will result in equilibration, and all exposed aquatic organisms will contain the residues. For example, considering the probable worldwide transport and precipitation of DDT, one would not expect to find any aquatic animal of appreciable fat content to be devoid of residues. (Gonads of the sea-star Acanthaster planci from several isolated and uninhabited Pacific atolls contained 0.68 p.p.m. of DDT ${ }^{100}$.)

(4) Given the time required for adjustment of the equilibrium - not necessarily long - the xenobiotic concentration in fat will be independent of source; 'bioconcentration' may occur in an organism, but the concept of food-chain 'biomagnification' among aquatic animals would not be valid.

In fact, a growing body of literature indicates that instances of sustained increases in residues with increasing trophic level may be quite limited and perhaps even unusual ${ }^{56,101-105}$. Once outside aquatic ecosystems, food undoubtedly becomes the principal avenue of exposure to toxicants for most animals, but metabolic rates, efficiency of biodegradation, selective absorption, and active excretion usually increase substantially; terrestrial vertebrates have evolved ways to compensate for the lack of surrounding water. Effective 'biomagnification' becomes much more a matter of chance. However, as species advance from the simple diffusion possible in lower aquatic invertebrates, absorption, transport and metabolism also increase rapidly in complexity, and 'single-compartment' concepts must yield to more complex expressions ${ }^{106}$.

While bioconcentration potential is not directly concerned with equilibration rates, the time factor has distinct practical importance. For one thing, the fat content of aquatic invertebrates can vary widely over a period of months, and extremely slow equilibration could complicate even a rough estimate of residue level. Further, the life span of many of the smaller aquatic forms doubtless is measured in months, and the duration of some juvenile stages in weeks; slow uptake would preclude attainment of the expected bioconcentration equilibrium. Although the Kerr-Vass model ${ }^{33}$ predicts 
that approach toward equilibrium requires periods far in excess of common lifespans, both laboratory and field observations with aquatic species indicate that rates of uptake, loss and equilibration can be quite rapid, depending upon the size of the animal. The apparent discrepancy in the model may be due in part to making the equilibration rate dependent upon a loss of compound proportional to metabolic rate (and weight), whereas metabolic rate is also involved with exposure and uptake.

Despite a sharp decline in the use of DDT and polychlorinated biphenyls in many countries, enormous quantities of other synthetic chemicals are produced whose properties suggest a pronounced bioconcentration potential (Table 2). History indicates that eventual accidental exposure of the aquatic environment (such as 'spills') appears inevitable, but routine prior estimation of the hazard followed by appropriate safeguards and controls seems only logical in view of recent experience with chlorinated hydrocarbons. This is not to say that persistent chemicals-including DDT- should not be manufactured and used with due regard for their properties; however, at least some simple test, such as that suggested here, could be applied to each intermediate and byproduct in manufacture and each major environmental transformation product in an attempt to avoid further nasty surprises. Eventually, more refined versions of the promising 'model ecosystems' ${ }^{107}$ could be profitably applied to the questionable cases, especially as we learn more about the real ecosystems themselves, and the use of bioconcentrating 'sentinel' organisms then might be established as routine.

Many bioconcentrated compounds at least reach detectable levels, and, perhaps because of that very stability, aquatic organisms often appear none the worse for their exposure. Non-persistent chemicals, including metabolites and other transformation products, present different and probably more difficult problems. Especially as more detailed and sophisticated ecosystem models are developed, the probability increases for exposure of their inhabitants to unnaturally high concentrations of each other's metabolites. It is quite conceivable that what represents a detoxication product of one species forms a water- or food-borne toxicant for another. Again, extension of laboratory data to field situations will be difficult but necessary.

Despite our environmental concerns, we should recognize that we are dealing with dynamic, evolving, living systems. Present-day aquatic animals are the living survirors of an evolutionary process in which response to toxic chemicals probably was an important factor. For example, after even rather brief periods of exposure fish, amphibians and aquatic invertebrates acquired resistance to DDT $^{31,108}$; alternate detoxication pathways exist for most types of compounds, and detoxication capacity can be induced ${ }^{92}$. Molluscs close their shells against toxicants, and more mobile aquatic animals no doubt simply swim away. The aquatic world inevitably will change, although we often seem to give our fellow creatures little credit for their ability to survive; that we should avoid making the change precipitous represents the purpose of this paper.

\section{ACKNOWLEDGEMENTS}

Expert assistance was provided by Charles Fischer and Richard Garnas, 
and financial support by the National Institute of Environmental Health Science (Research Grant ES-00054).

\section{REFERENCES}

${ }^{1}$ R. L. Rudd and R. E. Genelly, Pesticides: Their use and Toxicity in Relation to Wildlife, Game Bull. 7. Calif. Dept of Fish and Game: Sacramento, Calif. (1956).

2 R. Carson. Silent Spring. Houghton-Mifflin: Boston (1962).

${ }^{3}$ D. G. Crosby, Advanc. Chem. 111, 173 (1972).

D. G. Crosby and H. O. Tutass, J. Agr. Food. Chem. 14, 596 (1966).

${ }^{5}$ K. Munakata and M. Kuwahara, Residue Rev. 25, 13 (1969).

6 Y. L. Chen and J. E. Casida, J. Agr. Food Chem. 17, 208 (1969).

7 H.-M. Cheng, I. Yamamoto and J. E. Casida, J. Agr. Food Chem. 20, 850 (1972).

8 L. Lykken, in Environmental Toxicology of Pesticides (F. Matsumura, M. Boush and T. Misato, eds.), p 449. Academic Press: New York (1972).

9 D. G. Crosby and A. S. Wong, J. Agr. Food Chem. 21, 1052 (1973).

${ }^{10}$ R. D. Ross and D. G. Crosby, J. Agr. Food Chem. 21, 335 (1973).

11 G. L. Henderson and D. G. Crosby, Bull. Environ. Contam. Toxicol. 3, 131 (1968).

12 P. Koivistoinen and M. Meriläinen, Acta Agr. Scand. 12, 267 (1962).

13 J. G. Lamberton and R. R. Claeys, J. Agr. Food Chem. 18, 92 (1970).

14 D. G. Crosby and K. W. Moilanen, Bull. Environ. Contam. Toxicol. 10, 372 (1973).

15 J. L. Herring, E. J. Hannan and D. D. Bills, Bull. Environ. Contam. Toxicol. 8, 153 (1972).

${ }^{16}$ K. Anderson, $\AA$. Norström, C. Rappe, B. Rasmussen and H. Swahlin, Presented at the 166th National Meeting, Amer. Chem. Soc., Chicago, 26-31 August 1973).

17 S. G. Herman, R. L. Garrett and R. L. Rudd, in Chemical Fallout (M. N. Miller and G. G. Berg, eds.). C. C. Thomas: Springfield, Ohio (1969).

18 R. P. Miskus, D. P. Blair and J. E. Casida, J. Agr. Food Chem. 13, 481 (1965).

19 R. L. Rudd and S. G. Herman, in Environmental Toxicology of Pesticides (F. Matsumura, M. Boush and T. Misato, eds.), p 471. Academic Press: New York (1972).

20 F. Matsumura, in Environmental Toxicology of Pesticides (F. Matsumura, M. Boush and T. Misato, eds.), p 525. Academic Press: New York (1972).

21 F. Matsumura, K. C. Patil and G. M. Boush, Nature (London), 230, 325 (1971).

22 S. Jensen, R. Göthe and M.-O. Kindstedt, Nature (London), 240, 421 (1972).

23 D. G. Crosby, R. K. Tucker and N. Aharonson, Food Cosmet. Toxicol. 4, 503 (1966).

${ }^{24}$ H. O. Sanders, J. Water Poll. Contr. Fed. 2, 1544 (1970).

25 D. Pimentel, Ecological Effects of Pesticides on Non-Target Species. Exec. Office of the President, OST: Washington, DC (1971).

26 S. J. Parka and H. M. Worth, Proc. Southern Weed Conf. 18, 469 (1965).

27 P. A. Butler, in Biological Impact of Pesticides in the Environment (J.W. Gillette, ed.), p 87. Oregon State University: Corvallis (1970).

28 W. E. Odum, G. M. Woodwell and C. F. Wurster, Science, 164, 576 (1969).

29 H. C. Davis, Commercial Fisheries Rev. 23, 8 (1961).

30 G. D. Waugh and A. Ansell, Ann. Appl. Biol. 44, 619 (1956).

${ }^{31}$ S. M. Naqvi and D. E. Ferguson, J. Mississippi Acad. Sci. 14, 121 (1960).

32 D. W. Albaugh, Bull. Environ. Contam. Toxicol. 8, 334 (1972).

33 J. R. Kerr and W. P. Vass, in Environmental Pollution by Pesticides (C. A. Edwards, ed.), p 134. Plenum Press; London (1973).

34 J. L. Cox, Fishery Bull. 69, 443 (1971).

35 D. B. Seba and E. F. Corcoran, Pesticide Monitor. J. 3, 190 (1969).

36 A. R. Wolcott, in Pesticides in the Soil, p 128. Michigan State University: East Lansing, Michigan (1970).

37 J. W. Hamaker and J. M. Thompson, in Organic Chemicals in the Soil Environment (C. A. I. Goring and J. W. Hamaker, eds.), Vol. I, p 51. Dekker: New York (1972).

38 A. Södergren, Oikos, 19, 126 (1968).

39 J. L. Cox, Bull. Environ. Contam. Toxicol. 5, 218 (1970).

40 R. E. Reinert, Pesticide Monitor. J. 3, 233 (1970).

${ }^{41}$ K. J. Macek, in Biological Impact of Pesticides in the Environment (J. W. Gillett, ed.), p 17. Oregon State University: Corvallis (1970). 


\section{DONALD G. CROSBY}

42 G. M. Woodwell, C. F. Wurster and P. A. Isaacson, Science, 156, 821 (1967).

43 K. J. Macek and S. Korn, J. Fish. Res. Board Canada, 27, 1496 (1970).

44 J. L. Cox, Fishery Bull. 69, 627 (1971).

45 L. F. Stickel, Organochlorine Pesticides in the Environment, Special Scientific Report, Wildlife No. 119. US Dept. Interior: Washington, DC (1968).

46 M. C. Bowman, F. Acree Jr and M. K. Corbett, J. Agr. Food Chem. 8, 406 (1960).

47 F. A. Gunther, W. E. Westlake and P. S. Jaglan, Residue Rev. 20, 1 (1968).

${ }^{48}$ K. S. Park and W. N. Bruce, J. Econ. Ent. 61, 770 (1968).

49 J. W. Biggar, G. R. Dutt and R. L. Riggs, Bull. Environ. Contam. Toxicol. 2, 90 (1967).

${ }^{50}$ H. Lipke and C. W. Kearnes, J. Econ. Ent. 53, 31 (1960).

51 R. L. Wershaw, P. J. Burcar and M. C. Goldberg, Environ. Sci. Technol. 3, 271 (1969).

52 W. N. Yule and A. D. Tomlin, Bull. Environ. Contam. Toxicol. 5, 479 (1971).

53 P. S. Galtsoff, The American Oyster, Fishery Bull. 64. Fish and Wildlife Service, US Dept. of Interior: Washington, DC (1964).

${ }^{54}$ E. F. Ricketts, J. Calvin and J. W. Hedgpeth, Between Pacific Tides, 4th ed. Stanford University Press: Stanford, Calif. (1968).

55 J. H. Ryther, Ecology, 5, 522 (1954).

56 J. L. Hamelink, R. C. Waybrant and R. C. Ball, Trans. Amer. Fish Soc. 100, 207 (1971).

57 B. T. Johnson, C. R. Saunders, H. O. Sanders and R. S. Campbell, J. Fish. Res. Board Canada, 28, 705 (1971).

58 M. A. Q. Khan, A. Kamal, R. J. Wolin and J. Runnels, Bull. Environ. Contam. Toxicol. 8, 219 (1972).

59 A. Södergren and B. Svensson, Bull. Environ. Contam. Toxicol. 9, 345 (1973).

60 D. G. Crosby and R. K. Tucker, Environ. Sci. Technol. 5, 714 (1971).

61 N. V. Brodtmann, Bull. Environ. Contam. Toxicol. 5, 455 (1970).

62 A. V. Holden, Annals Appl. Biol. 50, 467 (1962).

63 P. G. Murphy and J. V. Murphy, Bull. Environ. Contam. Toxicol. 6, 581 (1971).

${ }^{64}$ J. H. Gakstatter and C. M. Weiss, Trans. Amer. Fish. Soc. 6, 301 (1967).

65 D. E. Ferguson, J. L. Ludke and G. G. Murphy, Trans. Amer. Fish Soc. 95, 335 (1966).

66 A. R. Grzenda, W. J. Taylor and D. F. Paris, Trans. Amer. Fish. Soc. 100, 215 (1971).

67 D. R. Nimmo, A. J. Wilson Jr and R. R. Blackman, Bull. Environ. Contam. Toxicol. 5, 333 (1970).

68 P. A. Butler, in National Symposium on Estuarine Pollution, p 107. Stanford University: Stanford, Calif. (1967).

69 J. A. Kawatski and J. C. Schmulbach, Intern. J. Environ. Anal. Chem. 1, 283 (1972).

70 T. J. Peterle. in The Biological Impact of Pesticides in the Environment (J. W. Gillette, ed.) p 11. Oregon State University: Corvallis (1970).

71 J. E. Keil and L. E. Priester, Bull. Environ. Contam. Toxicol. 4, 169 (1969).

72 P. G. Murphy, Bull. Environ. Contam. Toxicol. 5, 404 (1970).

73 E. E. Kenaga, in Environmental Toxicology of Pesticides (F. Matsumura, M. Boush and T. Misato, eds.), p. 193. Academic Press: New York (1972).

74 E. E. Kenaga, Residue Rev. 44, 73 (1972).

75 M. Beroza, M. N. Inscoe and M. C. Bowman, Residue Rev. 30, 1 (1969).

76 S. Voerman, Bull. Environ. Contam. Toxicol. 4, 64 (1969).

77 C. A. I. Goring, in Organic Chemicals in the Soil Environment (C. A. I. Goring and J. W. Hanmaker, eds.), Vol. II, p 793. Dekker: New York (1972).

78 V. L. Loosanoff, in Research in Pesticides (C. O. Chichester, ed.), p 135. Academic Press: New York (1965).

79 V. D. Sidwell, J. C. Bonnet and E. G. Zook, Marine Fisheries Rev. 35, 16 (1973).

80 J. Mauchline and L. R. Fisher, Advances Marine Biol. 7, 1 (1969).

${ }^{81}$ L. Renaud, Ann. Inst. Oceanog. (Paris), 24, 259 (1949).

82 W. Bergman, J. Marine Res. 8, 137 (1949).

83 R. R. Lee, J. C. Nevenzel and G.-A. Paffenhöfer, Science, 167, 1510 (1970).

84 C. H. Hansch, R. M. Muir, T. Fujita, P. P. Maloney, F. Geiger and M. Streich, J. Amer. Chem. Soc. 85, 2817 (1963).

85 D. Mackay and A. W. Wolkoff, Environ. Sci. Technol. 7, 611 (1973).

${ }^{86}$ D. G. Crosby, Residue Rev. 25, 1 (1969).

87 A. Verloop, Residue Rev. 43, 55 (1972).

88 O. B. Cope, J. P. McCraren and L. Eller, Weed Sci. 17, 158 (1969). 


\section{THE TOXICANT-WILDLIFE COMPLEX}

${ }^{89}$ G. E. Walsh, C. W. Miller and P. T. Heitmuller, Bull. Environ. Contam. Toxicol. 6, 279 (1971).

90 B. B. Brodie and R. P. Maickel, in Metabolic Factors Controlling Drug Design (B. B. Brodie and E. G. Erdos, eds.), p 299. MacMillan: New York (1962).

91 J. N. Smith, Adv. Compar. Physiol. Biochem. 3, 173 (1968).

92 L. C. Terriere, in The Enzymatic Oxidation of Toxicants (E. Hodgson, ed.), p 175. North Carolina State University: Raleigh (1968).

93 I. Nabih and J. Metri, J. Pharm. Sci. 60, 1242 (1971).

94 V. Ullrich and H. Staudinger, in Microsomes and Drug Oxidations (J. R. Gillette, et al., eds.), p 199. Academic Press: New York (1969).

95 D. G. Crosby, in Degradation of Synthetic Organic Molecules in the Biosphere, p 260. National Academy of Sciences: Washington, DC (1972).

96 D. G. Crosby and C.-S. Tang, J. Agr. Food. Chem. 17, 1041 (1969).

97 W. Ernst and C. Böehme. Food Cosmet. Toxicol. 3, 789 (1965).

98 L. L. Eberhardt, R. L. Meeks and T. J. Peterle, Nature (London) 230, 60 (1971).

99 H. L. Harrison, O. L. Loucks, J. W. Mitchell, D. F. Parkhurst, C. R. Tracy, D. G. Watts and V. J. Yannacone Jr Science, 170, 503 (1970).

100 L. R. McCloskey and K. H. Deubert, Bull. Environ. Contam. Toxicol. 8, 251 (1972).

101 J. Robinson, A. Richardson, A. N. Crabtree, J. C. Coulson and G. R. Potts, Nature (London), 214, 1307 (1967).

102 T. J. Peterle, J. Appl. Ecol. 3 (Suppl.), 181 (1966).

103 J. O. Keith, J. Appl. Ecol. 3 (Suppl.), 71 (1966).

104 C. A. Edwards, Persistent Pesticides in the Environment, Chemical Rubber Co.: Cleveland (1970).

105 G. R. Harvey, H. P. Miklas. V. T. Bowen and W. G. Steinhauer, J. Marine Res. 32, 103 (1974).

106 J. Robinson, in Environmental Pollution by Pesticides (C. A. Edwards, ed.), p 459. Plenum Press: London (1973).

107 R. L. Metcalf, G. K. Sangha and I. P. Kapoor, Environ. Sci. Technol. 5, 709 (1971).

108 D. E. Ferguson, in The Biological Impact of Pesticides in the Environment (J. W. Gillett, ed.), p 83. Oregon State University: Corvallis (1970). 